OPEN ACCESS

Edited by:

Shokrollah Elahi,

University of Alberta, Canada

Reviewed by:

Isobel Okoye,

University of Alberta, Canada

Jianzhong Zhu,

Yangzhou University, China

*Correspondence:

Li Ma

maryhmz@126.com

Specialty section: This article was submitted

to HIV and AIDS,

a section of the journal

Frontiers in Immunology

Received: 17 May 2017

Accepted: 31 July 2017

Published: 16 August 2017

Citation:

Zhou C-Y, Wang R-N, Wen Q,

He W-T, Zhang S-M, Du X-L,

Yang J-H and Ma L (2017) Alanine

Mutagenesis in the Complementarity

Determining Region 3 of the MTB

and HIV-1 Peptide-Bispecific T Cell

Receptor Beta Chain Affects

Ligand Recognition.

Front. Immunol. 8:983.

doi: 10.3389/fimmu.2017.00983

\section{Alanine Mutagenesis in the Complementarity Determining Region 3 of the MTB and HIV-1 Peptide-Bispecific T Cell Receptor Beta Chain Affects Ligand Recognition}

\author{
Chao-Ying Zhou, Rui-Ning Wang, Qian Wen, Wen-Ting He, Shi-Meng Zhang, Xia-Lin Du, \\ Jia-Hui Yang and Li Ma*
}

Institute of Molecular Immunology, School of Laboratory Medicine and Biotechnology, Southern Medical University, Guangzhou, China

Mycobacterium tuberculosis/human immunodeficiency virus (MTB/HIV) coinfection presents a special challenge to the prevention and treatment of tuberculosis and HIV/ AIDS. Adoptive transfer of high-affinity T cell receptor (TCR) gene-modified T cells against MTB and HIV antigens is a promising approach to treating MTB/HIV coinfected patients whose cellular immunity is obviously disordered. We have previously successfully identified that a bispecific TCR screened out from peripheral blood mononuclear cells of a

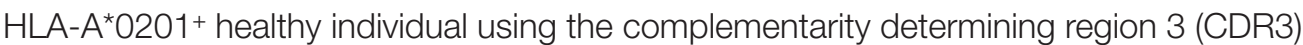
spectratype analysis recognizes both MTB Ag85B ${ }_{199-207}$ and HIV-1 Env 120-128 $_{12}$ peptide. However, it has not been known how residues on CDR3 loops, which have been shown to play a leading role in antigen binding and specificity contribute to the bispecific TCR contact with the peptide-major histocompatibility complex (MHC) complexes. In this study, we provided an extensive investigation of residues in the predicted CDR3 of the bispecific TCR beta ( $\beta$ ) chain using alanine scanning mutagenesis. Our data showed that three of the five substituted residues (G115A, T116A, A117G) in CDR3 $\beta$ of the bispecific TCR caused a significantly diminished $T$ cell response to antigen, whereas the remaining two substituted residues (D114A, S118A) resulted in completely eliminated response, thus identifying the two residues that were particularly critical for the recognition of peptide-MHC in the bispecific TCR. These findings will provide an imperative foundation for generating an improved high-affinity bispecific TCR for use in T cell adoptive immunotherapy for MTB/HIV coinfected individuals.

Keywords: alanine scanning mutagenesis, complementarity determining region $3 \beta$, bispecific $\mathrm{T}$ cell receptor, MTB/HIV coinfection, adoptive immunotherapy

\footnotetext{
Abbreviations: MTB, Mycobacterium tuberculosis; HIV, human immunodeficiency virus; TCR, T cell receptor; CDR3, complementarity determining region 3 ; MHC, major histocompatibility complex; $\beta$, beta; TB, tuberculosis; $\mathrm{V}$, variable; $\mathrm{D}$, diversity; J, joining; C, constant; PBMCs, peripheral blood mononuclear cells; FBS, fetal bovine serum; DCs, dendritic cells; IL-2, interleukin-2; WT, wild-type; AAs, amino acids; IFN- $\gamma$, interferon- $\gamma$; TNF- $\alpha$, tumor necrosis factor- $\alpha$; GM-CSF, granulocytemacrophage colony-stimulating factor; GrB, granzyme B; CCK-8, cell counting kit-8.
} 


\section{INTRODUCTION}

Mycobacterium tuberculosis/human immunodeficiency virus (MTB/HIV) coinfection presents a massive challenge to the prevention and treatment of tuberculosis (TB) and HIV/AIDS. HIV infection is the most powerful risk factor for development of active $\mathrm{TB}$, which remarkably increases the individual susceptibility to primary $\mathrm{TB}$ infection or reinfection and promotes reactivation of latent TB infection (1). TB also has an adverse impact on immune responses to HIV, which accelerates the course of disease from HIV infection to AIDS (1). Among the estimated 10.4 million new TB cases in 2015, about 1.2 million (11\%) were estimated to be HIV positive. There were an estimated 1.8 million TB deaths in 2015, among which about a quarter were people who were infected with HIV (2). Notwithstanding World Health Organization guidelines supporting long courses of concomitant anti-TB and antiretroviral therapies of the two diseases and urging more aggressive management, multiple problems such as potential drug interactions between rifampin and some kinds of antiretroviral drugs, cumulative drug toxicities, a high pill burden, the immune reconstitution inflammatory syndrome, and programmatic challenges still exist (3). Therefore, development of new therapeutic options for MTB/HIV coinfection has become imperative.

Mycobacterium tuberculosis and HIV are both intracellular pathogens that can be controlled by cellular immunity mediated by $\mathrm{T}$ cells. However, the immune function is obviously disordered in MTB/HIV coinfected patients, which mainly manifest as reduced number and declining function of effector T cells (4). Hence, cellbased immunotherapy based on increasing $\mathrm{T}$ cell numbers and improving $\mathrm{T}$ cell function is a promising approach for treating MTB/HIV coinfected patients. Adoptive T cell transfer has shown some prominent antitumor or anti-infection responses in patients with cancer and chronic infection (5-7). A main restriction of universal application of adoptive cellular immunotherapy is the difficulty in generating sufficient numbers of human $\mathrm{T}$ cells with antitumor or anti-infection potential. Rosenberg group has proved that about only half of melanomas reproducibly give rise to melanoma-specific lymphocyte (8). As an alternative method, high-affinity $\mathrm{T}$ cell receptors (TCRs) can be introduced into autologous $\mathrm{T}$ cells of the patients, and then transfer these antigen-specific TCR gene-modified T cells into lympho-depleted patients, which has shown notable therapeutic effect in treatment of metastatic melanoma (9), leukemia (10), hepatitis C-associated hepatocellular carcinoma (11), and HIV (12), cytomegalovirus (13), and Epstein-Barr virus infections (14).

Several lines of evidence suggest that TCR affinity is the primary factor for determining the avidity of $\mathrm{T}$ cells and the consequence of antigen stimulation $(15,16)$. The rigor of thymic positive and negative selection ensures that natural TCRs, which bind to widespread self or tumor-associated antigens possess virtually much lower affinities than when they bind to pathogen antigens (17). Native TCR-peptide-major histocompatibility complex (MHC) interactions have an extremely narrow window of affinities in the range of $0.1-500 \mu \mathrm{M}$ (18), which possibly reflect a balance between the need to efficiently activate $\mathrm{T}$ cells and the need to sustain immunologic self-tolerance (19). Within this range, TCR affinity is associated with antigen sensitivity (20), which puts self-antigen-specific $\mathrm{T}$ cells at an obvious disadvantage in comparison with their pathogen-reactive $\mathrm{T}$ cells. The transfer of genes encoding TCRs with affinities as high as those of the best antiviral T cells $\left(K_{\mathrm{d}}=100 \mathrm{nM}\right)$ into recipient T cells could offer optimal anti-infection immunity (18). Because TCRs with higher affinity do not appear in the mature $\mathrm{T}$ cell repertoire, understanding the molecular basis of natural TCRs, which requires the mutational analysis, will establish a foundation for obtaining the engineered high-affinity TCRs.

Alanine scanning mutagenesis within the complementarity determining regions (CDRs) of the $\alpha$ - and $\beta$-chains, which form the TCR heterodimer is a commonly used method of mutational analysis to illuminate the function of TCR amino acid (AA) residues in antigen complex binding as well as activation of $\mathrm{T}$ cells (21). CDRs that engage both the peptide and the MHC molecule are surface-exposed loops, which play a dominant role in determining the specificity of antigen recognition by TCR. As is well known, TCRs and peptide-MHC interactions are a twostep process whereby the CDR1 and CDR2 loops of the TCR first weakly contact the MHC $\alpha$-helices independent of the peptide and, subsequently, peptide contacts dominate stabilization and the peptide bound to MHC is recognized primarily by the hypervariable complementarity determining region 3 (CDR3) loops (22). Apparently, the TCR CDR3 regions have been shown to play a leading role in antigen binding and specificity. Several studies on alanine substitutions of TCR CDR3 residues have widely studied to determine the role of individual CDR3 residues on TCR affinity and functional avidity $(23,24)$. However, Rosenberg group has demonstrated that the TCR $\beta$-chain plays a more important role in antitumor response than the TCR $\alpha$-chain by comparing the functional activity of AIB ( $\alpha$-IRES- $\beta$ ) and BIA ( $\beta$-IRES- $\alpha$ ) TCRs-modified PBL (25). It is universally acknowledged that the $\alpha \beta$ TCR is assembled by a process of somatic gene rearrangement of variable $(\mathrm{V})$, diversity $(\mathrm{D})$, joining $(\mathrm{J})$, and constant $(\mathrm{C})$ gene fragments. The process includes stochastic $\mathrm{N}$-nucleotide insertions and deletions at VDJ junctions via VNDNJ in $\beta$ chain. Even the $\mathrm{V}(\mathrm{D}) \mathrm{J}$ junctions are to a large extent shared between different $\mathrm{T}$ cell clones (26). Therefore, in this article, alanine mutagenesis of the NDN region which is the most random and specific within the CDR $3 \beta$ of the bispecific TCR was firstly performed.

We have previously successfully identified that a bispecific TCR screened out from peripheral blood mononuclear cells (PBMCs) of a HLA- $\mathrm{A}^{*} 0201^{+}$healthy individual using the CDR3 spectratype analysis recognizes both MTB $\mathrm{Ag}_{85} \mathrm{~B}_{199-207}$ and HIV-1 Env ${ }_{120-128}$ peptide (27). However, it has not been known how residues on CDR3 loops contribute to the bispecific TCR contact with the peptide-MHC complexes. In this report, we provided an extensive investigation of residues in the predicted CDR $3 \beta$ of the bispecific TCR using single AA substitutions. Our data showed that three of the five substituted residues in CDR3 $\beta$ of the bispecific TCR caused a markedly diminished $\mathrm{T}$ cell response, whereas the remaining two alanine substitutions resulted in completely eliminated antigen response. These findings will provide an imperative foundation for generating the engineered high-affinity bispecific TCR for use in T cell adoptive immunotherapy for MTB/HIV coinfected individuals. 


\section{MATERIALS AND METHODS}

\section{Cell Lines and Primary Cells}

The 293T human embryonic kidney cells (ATCC CRL-11268) used for lentiviral production were cultured in Dulbecco's modified Eagle's medium (Corning, NY, USA) supplemented with $10 \%$ fetal bovine serum (FBS; Corning), 1\% GlutaMAX-I (Thermo Fisher Scientific Inc., MA, USA), and 1\% Minimum Essential Medium Non-Essential Amino Acids (Thermo Fisher Scientific Inc.). T2, which is a lymphoblastoid cell line deficient in TAP function, whose HLA-A ${ }^{\star} 0201$ molecules can be easily loaded with exogenous peptides, was grown in Iscove's modified Dulbecco's medium (Corning) contained with 20\% FBS. The J.RT3-T3.5 cell line (kindly provided by Dr. Wei He, Peking Union Medical College, Beijing, China), which is a derivative mutant of the Jurkat leukemia cell line lacking surface expression of TCR $\alpha / \beta$ heterodimer and CD3 due to a defect in the TCR $\beta$-chain, was maintained in 10\% FBS RPMI-1640 (Corning).

Peripheral blood mononuclear cells were isolated from blood of a HLA-A ${ }^{\star} 0201$ healthy donor with informed consent by FicollHypaque (Axis-Shield Diagnostics Ltd., Dundee, Scotland, UK) density gradient centrifugation. The research had been carried out in accordance with the World Medical Association Declaration of Helsinki and was approved by the ethics committee of the Southern Medical University. Monocyte-derived dendritic cells (DCs) were induced from the autologous PBMCs as previously described (28). CD8 ${ }^{+} \mathrm{T}$ cells were sorted from PBMCs using antiCD8-labeled MACS magnetic beads (Miltenyi Biotec, Bergisch Gladbach, Germany) and were activated for 3 days by anti-CD3 $(1 \mu \mathrm{g} / \mathrm{ml})$, anti-CD28 $(1 \mu \mathrm{g} / \mathrm{ml}) \mathrm{mAbs}$ (BD Pharmingen, San Jose, CA, USA), and $100 \mathrm{U} / \mathrm{ml}$ interleukin-2 (IL-2; PeproTech, Rocky Hill, NJ, USA). Purified cells were then grown in RPMI-1640 medium contained with $10 \%$ FBS and $100 \mathrm{U} / \mathrm{ml}$ IL-2. All cells were cultured in a $37^{\circ} \mathrm{C}$ and $5 \% \mathrm{CO}_{2}$ incubator.

\section{Generation of Lentiviral Vectors Encoding Wild-type (WT) and Variant TCRs}

The MTB Ag85B $199-207$ and HIV-1 Env E20-128 $_{10}$ bispecific TCR $\alpha 17$ and $\beta 15$ genes identified by TCR CDR3 spectratype analysis (Figure 1A) as described in our previous study (27) were amplified from the plasmid pMX- $\beta 15-\mathrm{P} 2 \mathrm{~A}-\alpha 17-\mathrm{IRES}-\mathrm{GFP}$ by PCR. Nine AAs in the $C$ regions were replaced by murine counterparts as described previously (27). TCR $\alpha$ - and $\beta$-chains were linked with furin (RAKR)-linker (SGSG)-P2A ribosomal skip peptide sequence (29) by recombinant PCR. To increase translation efficiency, a Kozak consensus sequence (27) was included around the V $\alpha$ ATG.

Briefly, to achieve the WT TCR $\beta 15$-fuSGSGP2A- $\alpha 17$ gene, the plasmid pMX- $\beta 15-P 2 A-\alpha 17-I R E S-G F P$ was first used as the template. The forward primer P1 and the reverse primer P2 (containing $5^{\prime}$-end of fuSGSGP2A) were used to generate the $\beta$-chain containing $5^{\prime}$-end of fuSGSGP2A (hereinafter referred to as S1). The primers P3 (containing $3^{\prime}$-end of fuSGSGP2A) and $\mathrm{P} 4$ were used to generate the $\alpha$-chain containing $3^{\prime}$-end of fuSGSGP2A (fragment S2). Using S1 and S2 as the templates, the WT $\beta 15$-fuSGSGP2A- $\alpha 17$ fragment was amplified using P1 and
P4 primers. For generating the variant TCR $\beta$-chains, the $5^{\prime}$-end $\beta 15$ fragment was amplified from the WT $\beta 15$-fuSGSGP2A- $\alpha 17$ construct using the forward primer P1 and the reverse primer P5, P7, P9, P11 or P13, and the 3 '-end $\beta 15$-fuSGSGP2A- $\alpha 17$ fragment was generated using the forward primer P6, P8, P10, P12, or P14 and the reverse primer $\mathrm{P} 4$. The corresponding fragments were then mixed and joined by carrying out a PCR using P1 and P4 primers to produce the variant TCR genes. The DNA fragments containing the WT and variant TCRs were then digested and inserted into the pHAGE-fullEF1a-MCS-IZsGreen lentiviral vector at $\mathrm{XbaI}$ and BamHI sites. All of the primers (P1-P14) are outlined in Table 1.

\section{Production of Recombinant Lentiviral Particles}

The 293T human embryonic kidney cells were passaged the day before infection to achieve $70-80 \%$ confluence at infection. Cells were transfected with the lentivirus triad of plasmids pHAGE, psPAX2, and pMD2.G using X-tremeGENE HP DNA Transfection Reagent (Roche, Mannheim, Germany) following the manufacturer's instructions. Viral supernatants were harvested 48-72 h later. After filtering through a $0.45 \mu \mathrm{m}$ filter (Millipore, Bedford, MA, USA), the supernatants were concentrated by ultracentrifugation at $50,000 \mathrm{~g}, 4^{\circ} \mathrm{C}$, for $90 \mathrm{~min}$. The recombinant lentiviral particles were recovered and aliquots were sharp-frozen at $-80^{\circ} \mathrm{C}$. Viral titers were evaluated on $293 \mathrm{~T}$ cells by adding serial dilutions of concentrated virus suspension to $1 \times 10^{5}$ cells in a 12 -well plate (Nunc, Roskilde, Denmark) in the presence of polybrene $(8 \mu \mathrm{g} / \mathrm{ml}$; Sigma-Aldrich, St. Louis, MO, USA). Cells were analyzed 3 days after transduction for GFP expression by flow cytometry. Transduction activity was expressed in transduction units.

\section{Genetic Modification of CD8 ${ }^{+}$T Cells}

$\mathrm{CD}^{+} \mathrm{T}$ cells were plated at $1 \times 10^{6}$ cells $/ \mathrm{ml}$ in 6 -well plates (Nunc) in 10\% FBS RPMI-1640 medium supplemented with $100 \mathrm{U} / \mathrm{ml} \mathrm{IL}-2,1 \mu \mathrm{g} / \mathrm{ml}$ anti-CD3, and $1 \mu \mathrm{g} / \mathrm{ml}$ anti-CD28 $\mathrm{mAbs}$ $72 \mathrm{~h}$ before transduction. The concentrated lentivirus suspension containing $8 \mu \mathrm{g} / \mathrm{ml}$ polybrene was added and after $4 \mathrm{~h}$ incubation, the fresh medium was supplemented to dilute the polybrene to $2 \mu \mathrm{g} / \mathrm{ml}$. The procedure was repeated for an additional 2 days (total of three transductions). Five days after the third transduction (total of 8 days for infection), gene-modified $\mathrm{CD}^{+} \mathrm{T}$ cells were collected to eliminate the dead cells using the Dead Cell Removal Kit (Miltenyi Biotec) and detect the expression of GFP and incubated with APC-Cy7-anti-CD8 (Biolegend, San Diego, CA, USA), PE-labeled Ag85B ${ }_{199-207} / \mathrm{HLA}^{*}{ }^{*} 0201$ dextramer (Immudex, Copenhagen, Denmark) and APC-labeled $\mathrm{Env}_{120-128} / \mathrm{HLA}-\mathrm{A}^{\star} 0201$ dextramer (Immudex) according to the manufacturer's instructions to detected the exogenous TCRs by flow cytometry. In addition, RNA was extracted from transduced $\mathrm{CD}^{+} \mathrm{T}$ cells using E.Z.N.A. ${ }^{\circledR}$ Total RNA Kit (OMEGA Biotek, Inc., Norcross, GA, USA), and reverse transcription was performed using RevertAid ${ }^{\mathrm{TM}}$ First Strand cDNA Synthesis Kit (Thermo Fisher Scientific, Inc.). Transcription of exogenous TCR genes was verified by PCR. Primer sequences used to amplify a 


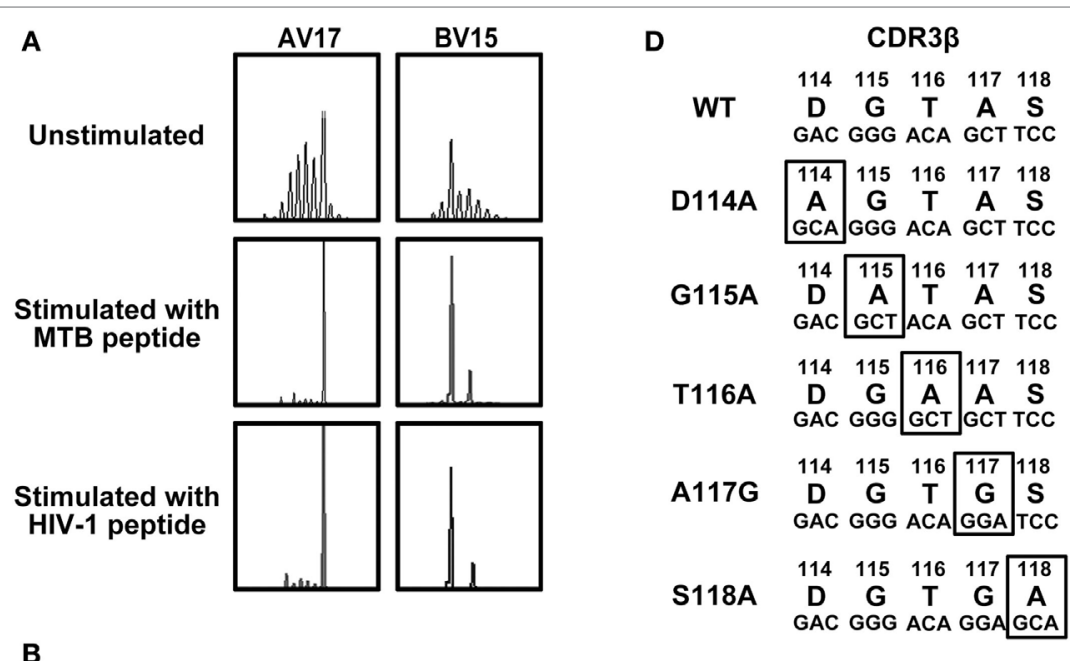

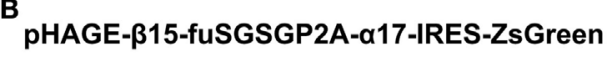

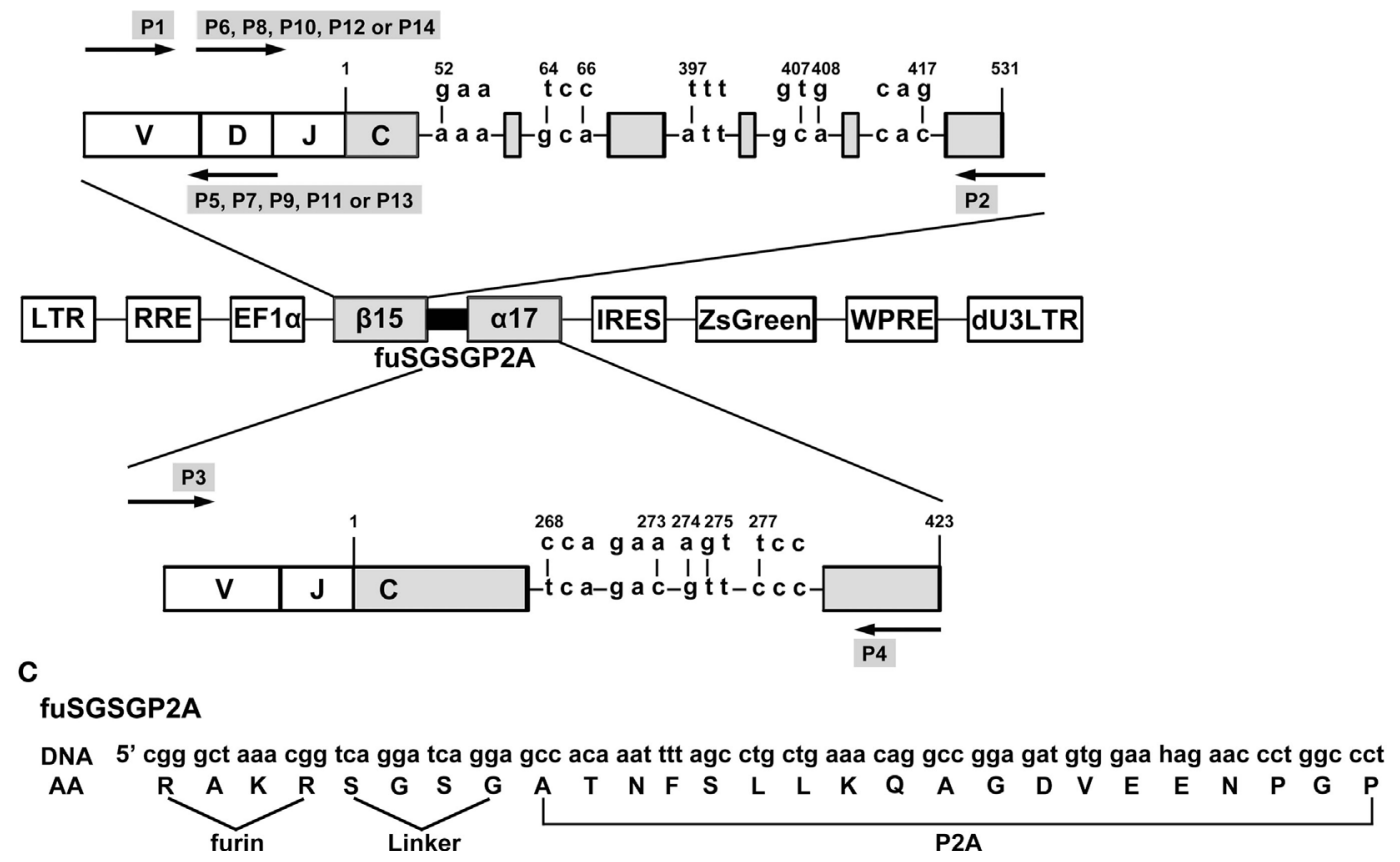

FIGURE 1 | Construction of lentiviral vectors expressing WT and variant bispecific T cell receptors (TCRs). (A) Complementarity determining region 3 (CDR3) spectratypes of TCR $\vee_{\alpha} 17$ and $V \beta 15$ gene families of CD8 ${ }^{+}$T cells before and after MTB Ag85B $199-207$ (KLVANNTRL) peptide or HIV-1 EnV $120-128$ (KLTPLCVTL) peptide stimulation. (B) Schematic illustration of the lentiviral vector encoding WT or variant bispecific TCRs. TCR $\beta$ - and $\alpha$-chains were linked with furin-SGSG-P2A. Nine critical AAs in the $C$ regions of $\beta 15$ and $\alpha 17$ were replaced by their murine counterparts. (C) Details of furin-SGSG-P2A sequences. (D) Alanine substitutions at the CDR3 region of the bispecific TCR $\beta$-chain. AV, TCR $V_{\alpha}$-chain; BV, TCR V $\beta$-chain; DNA: the DNA sequence; AA: the amino acid sequence; WT: wild-type.

portion of GAPDH and $\beta 15$-fuSGSGP2A- $\alpha 17$ from human CD8 ${ }^{+}$ $\mathrm{T}$ cells are summarized in Table $\mathbf{1}$.

\section{Cytokine Release Assays}

T2 cells pulsed with HLA-A*0201-restricted MTB Ag85B $B_{199-207}$ peptide (KLVANNTRL), HIV-1 Env ${ }_{120-128}$ peptide (KLTPLCVTL), or CMV pp65 $5_{495-503}$ peptide (NLVPMVATV) $(10 \mu \mathrm{g} / \mathrm{ml}$, or as described in figure legends; Proimmune, Oxford, UK) for $3 \mathrm{~h}$ at $37^{\circ} \mathrm{C}$ were incubated with CD $8^{+} \mathrm{T}$ cells. If IL- 2 was the cytokine measured, the cells were washed with media without IL-2 prior to coculture. For these assays, $1 \times 10^{5}$ effector cells $\left(\mathrm{CD} 8^{+}\right.$ $\mathrm{T}$ cells) and $1 \times 10^{5}$ stimulator cells (T2 cells) were incubated in individual wells of 96-well $U$-bottom plate (Nunc) with a total volume of $0.2 \mathrm{ml}$ for $24 \mathrm{~h}$, except interferon- $\gamma$ (IFN- $\gamma$ ), which was measured after $18 \mathrm{~h}$ of incubation. In some groups, DCs were transfected with the pV1J.ns-tPA-Ag85B plasmid (gifted by Dr. Kris Huygen in Pasteur Institute of Brussels, Brussels, Belgium) or the pCAGGS-Env plasmid (gifted by Dr. James M. Binley in Torrey Pines Institute for Molecular Studies, San Diego, CA, USA), respectively, using Lipofectamine 2000 Transduction 
TABLE 1 | Primers used for amplification of WT and variant T cell receptors.

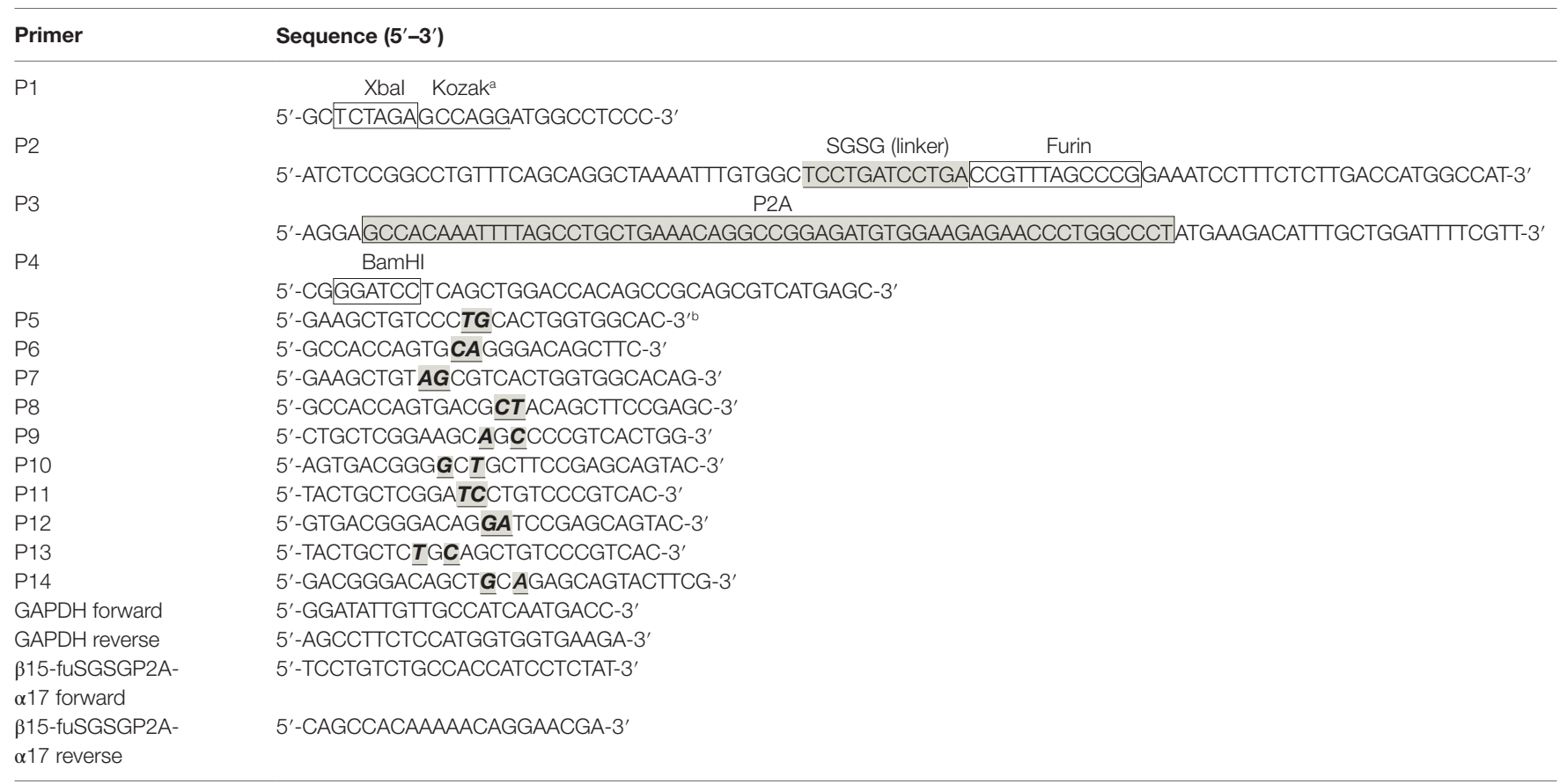

aKozak sequence, a nucleotide sequence located in the $5^{\prime}$ untranslated mRNA region that allows ribosomes to recognize the initiator codon, was underlined.

${ }^{b}$ Mutated nucleotides were labeled underlined, bold, tilted, and shadowed simultaneously.

Reagent (Invitrogen, Carlsbad, CA, USA). Cytokines were measured using IFN- $\gamma$, tumor necrosis factor- $\alpha$ (TNF- $\alpha$ ), IL-2, granulocyte-macrophage colony-stimulating factor (GM-CSF) ELISA kits (ExCell Bio, ShangHai, China), and granzyme B (GrB) ELISA Kit (eBioscience, San Diego, CA, USA) according to the manufacture's protocols.

\section{T Cell Proliferation Assays}

T-cell proliferation was assessed using Cell Counting Kit-8 (CCK-8; Dojindo, Kumamoto, Japan) according to the manufacturer's instructions. Briefly, $5 \times 10^{4} \mathrm{CD}^{+} \mathrm{T}$ cells were cocultured with $5 \times 10^{4}$ peptide pulsed T2 cells in a 96-well $U$-bottom plate. After incubating for 2,4 , or 7 days, $100 \mu \mathrm{l} /$ well of cell suspension was transferred into empty wells and $10 \mu \mathrm{l} /$ well CCK- 8 solutions were added. The plate was incubated at $37^{\circ} \mathrm{C}$ for $4 \mathrm{~h}$, and the absorbance at $450 \mathrm{~nm}$ was measured using a spectral scanning multimode reader (Thermo Scientific Varioskan Flash, Thermo Fisher Scientific, Inc.).

\section{Intracellular Cytokine Staining}

The genetically engineered $\mathrm{T}$ cells were also identified by flow cytometric analysis to assess intracellular IFN- $\gamma$ production. Briefly, TCR gene-modified $\mathrm{CD}^{+} \mathrm{T}$ cells were stimulated by $\mathrm{Ag}_{85 \mathrm{~B}_{199-207}, \mathrm{Env}_{120-128} \text {, or pp65 }}{ }_{495-503}$-loaded T2 cells in the presence of IL-2 $(50 \mathrm{U} / \mathrm{ml})$ for $18 \mathrm{~h}$ and then $10 \mu \mathrm{g} / \mathrm{ml}$ brefeldin A (Sigma-Aldrich) was added. After four additional hours of stimulation, $2 \times 10^{6}$ of cocultured cells were stained with PE-labeled Ag85B $_{199-207} / \mathrm{HLA}-\mathrm{A}^{\star} 0201$ dextramer, APC-labeled Env ${ }_{120-128} /$ $\mathrm{HLA}^{*}{ }^{\star} 0201$ dextramer, and APC-Cy7-anti-CD8, fixed and permeabilized according to the manufacturer's instructions (Cytofix/Cytoperm $^{\mathrm{TM}}$ Fixation/Permeabilization Solution Kit, BD Pharmingen), followed by intracellular staining with PE-Cy7anti-IFN- $\gamma$ (eBioscience).

\section{EuTDA Cytotoxicity Assays}

Cytotoxic activity of TCR-modified $\mathrm{CD}^{+} \mathrm{T}$ cells was determined using a DELFIA EuTDA cytotoxicity kit (Perkin-Elmer Life Sciences, Norwalk, CT, USA). Eu-labeled T2 cells or autologous DCs $\left(5 \times 10^{3}\right)$ were incubated with transduced $\mathrm{CD}^{+} \mathrm{T}$ cells at the effector: target ratio of 30:1 (or as described in figure legends) for $4 \mathrm{~h}$ at $37^{\circ} \mathrm{C}$. The plates were centrifugated and $20 \mu \mathrm{l}$ of supernatants from each well were transferred to a fresh 96-well microtitration plate, which contained $200 \mu \mathrm{l}$ of Eu Solution in each well. Fluorescence was detected using a Wallac Victor 2 Multilabel Counter (Perkin-Elmer Life Sciences, Norwalk, CT, USA). Percentage cytotoxicity was calculated by the following formula: [(experimental release - spontaneous release)/(maximum release - spontaneous release) $] \times 100$.

\section{CD107a Degranulation Assays}

In cytotoxic T cells, the cell surface mobilization of the CD107a was assessed as a marker for degranulation of lytic granules. In brief, $5 \times 10^{5}$ gene-transduced $\mathrm{CD}^{+} \mathrm{T}$ cells were incubated with $5 \times 10^{5}$ peptide-pulsed T2 cells for $4 \mathrm{~h}$ in the presence of $10 \mu \mathrm{g} / \mathrm{ml}$ brefeldin A and $5 \mu \mathrm{l} \mathrm{PE-anti-CD107a} \mathrm{(eBioscience).} \mathrm{After} \mathrm{the}$ incubation, the cells were harvested, washed, and stained with antibody specific for CD8. Data analysis was performed by Flow cytometry. 


\section{Expression of CD69 in Gene-Modified J.RT3-T3.5 Cells}

J.RT3-T3.5 cells were seeded at a density of $5 \times 10^{5}$ cells $/ \mathrm{ml}$ in RPMI-1640 into 6-well plates before transduction and then incubated with concentrated lentivirus suspension. After 3 days of transduction, genetically engineered J.RT3-T3.5 cells were collected and cocultured with peptide-pulsed T2 cells. Eighteen hours later, the cocultured cells were collected, washed, and stained with APC-anti-CD69 (eBioscience) according to the manufacturer's protocol. Data were analyzed by FACS.

\section{Statistical Analysis}

All statistical analyses were performed using the SPSS version 17.0 for windows (SPSS, Chicago, IL, USA). A one-way ANOVA and multiple comparisons tests (least significant difference or Dunnett's T3) were used to compare the differences between the experimental groups. $P$-values were two-sided. Differences with $P<0.05$ were considered significant.

\section{RESULTS}

\section{WT and Variant TCRs Vectors Construction}

The MTB Ag85B ${ }_{199-207}$ and HIV-1 Env $_{120-128}$ bispecific TCR $\alpha 17$ and $\beta 15$ genes were identified by TCR CDR3 spectratype analysis (Figure 1A) as described in our previous study (27). The lentiviral vector, $\mathrm{pHAGE}-\beta 15$-fuSGSGP2A- $\alpha 17$-IRES-IZsGreen, was constructed incorporating genes encoding $\beta$ - and $\alpha$-chains joined by furin (RAKR)-linker (SGSG)-P2A peptide sequence (Figures 1B,C). In this case, P2A was used to ensure equimolar production of $\beta$ - and $\alpha$-chain through a ribosomal skip mechanism. Addition of amino-acid linker (SGSG) before the P2A sequence could efficiently synthesize functionally active TCR. A furin cleavage site, which could be recognized in lymphocytes and facilitate removal of residual P2A peptide from the $\beta$-chain at the posttranslational level was incorporated at the $5^{\prime}$-end of the linker. To promote preferential pairing and improve cell surface expression of the exogenous TCR, nine critical AAs in the TCR $\alpha$ and $\beta$ C regions were replaced by murine counterparts as described previously (27).

The AA residues 114-118 (DGTAS) of the TCR CDR3 $\beta$ were targeted for substitution (Figure 1D). Aspartic acid, glycine, threonine, and serine at positions $114,115,116$, and 118 , respectively, were substituted with alanine (designated D114A, G115A, T116A, and S118A, respectively), and alanine at position 117 were replaced with glycine (designated A117G). Using the primers listed in Table 1, these constructs containing single AA substitution were produced.

\section{TCR Expression of Transduced T Cells}

After 5 days of the third lentiviral transduction, green fluorescence was clearly observed in empty vector transduced cultures and the WT and variant TCRs gene-modified $\mathrm{CD}^{+} \mathrm{T}$ cells (Figure 2A). As there is no commercial anti-V $\alpha 17$ or V $\beta 15$ antibody, MHC dextramers were used to determine the expression of transduced TCRs and assess TCRs affinity. Measurement by

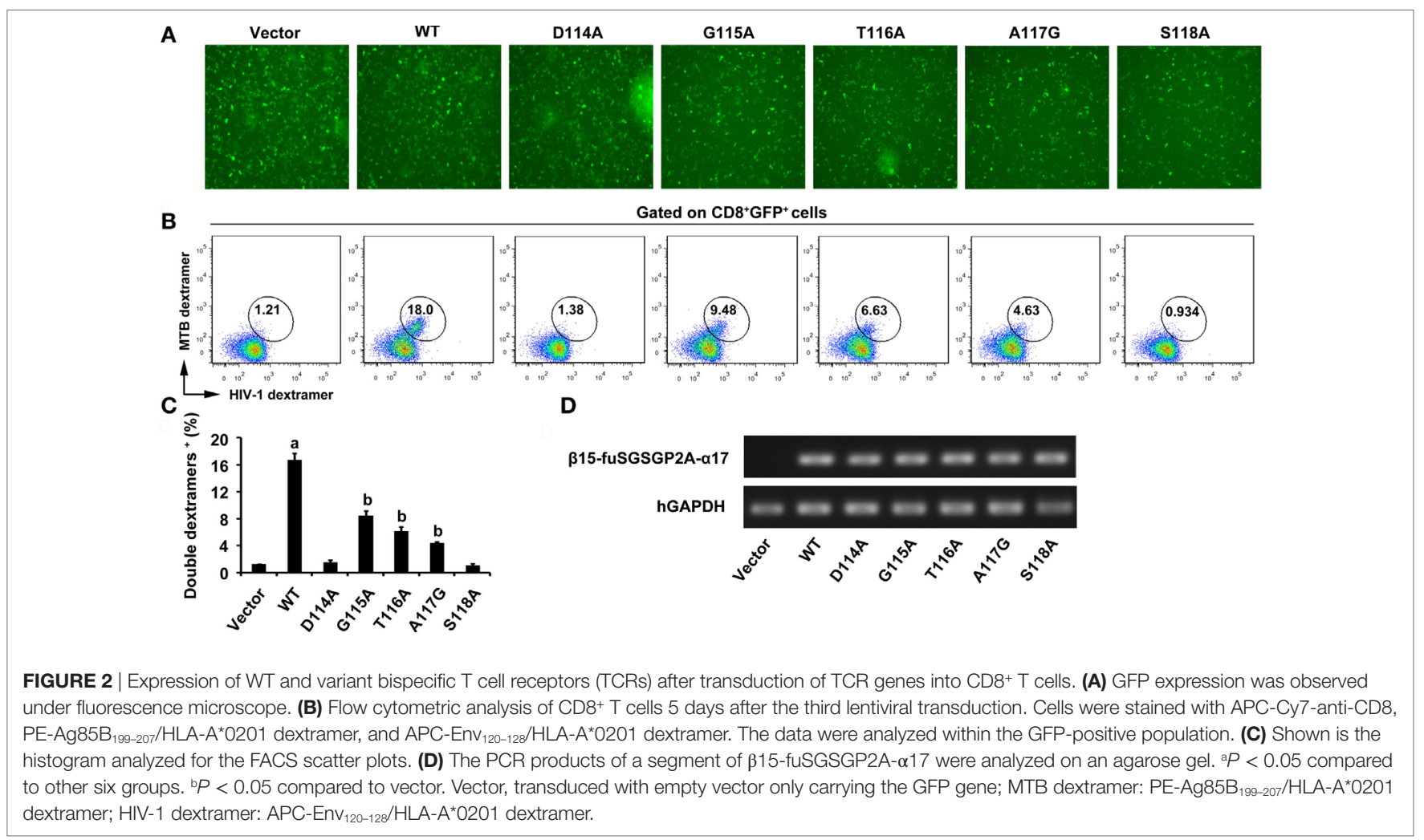


flow cytometry showed that about $16 \%$ of the $\mathrm{CD} 8^{+} \mathrm{T}$ cells were

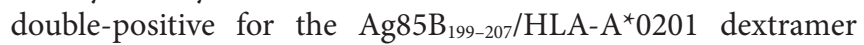
and $\mathrm{Env}_{120-128} / \mathrm{HLA}-\mathrm{A}^{\star} 0201$ dextramer within the GFP-positive population in the WT TCR-transduced cultures, which was significantly higher than other groups $(P<0.05)$. Similar percentage levels of double-dextramers staining were observed on $\mathrm{CD}^{+}$ $\mathrm{T}$ cells transduced with the G115A, T116A, and A117G TCRs, which showed a significant increase compared with empty vector transduced T cells, respectively $(P<0.05)$. Significant difference of the level of double-dextramers binding was not observed between $\mathrm{CD}^{+} \mathrm{T}$ cells transduced with the D114A TCR construct and empty vector transduced T cells $(P>0.05)$, as well as the S118A TCR transductant (Figures 2B,C). Transcription of transduced TCR genes was further verified by PCR. The electrophoretic band of a segment of $\beta 15$-fuSGSGP2A- $\alpha 17$ was clearly observed in the WT and variant TCRs transductants, while it was not observed in the empty vector transduced cells (Figure 2D).

\section{Cytokine Release in the WT and Variant TCRs Transductants}

To evaluate the function of the bispecific TCR CDR3 $\beta$ variants in $\mathrm{CD}^{+} \mathrm{T}$ cells, the effector cytokines were measured. The WT TCR gene-modified $\mathrm{CD}^{+} \mathrm{T}$ cells stimulated by either MTB Ag85B ${ }_{199-207}$ peptide or HIV-1 Env ${ }_{120-128}$ peptide-pulsed T2 cells secreted significantly higher levels of IFN- $\gamma$ than other groups $(P<0.05)$. Compared with untransduced or empty vector transduced T cells, the G115A, T116A, or A117G TCR transductant when cocultured with T2 cells loaded with MTB peptide or HIV-1 peptide showed a significant increase in IFN- $\gamma$ secretion $(P<0.05)$, while the D114A and S118A TCR transductants did not $(P>0.05)$ (Figure 3A). Similarly, the WT TCR-transduced $\mathrm{CD}^{+} \mathrm{T}$ cells specifically produced significant levels of TNF- $\alpha$ when exposed to MTB peptide or HIV-1 peptide-pulsed T2 cells compared with other groups $(P<0.05)$. CD $8^{+} \mathrm{T}$ cells transduced with G115A, T116A, or A117G TCR variant when cocultured

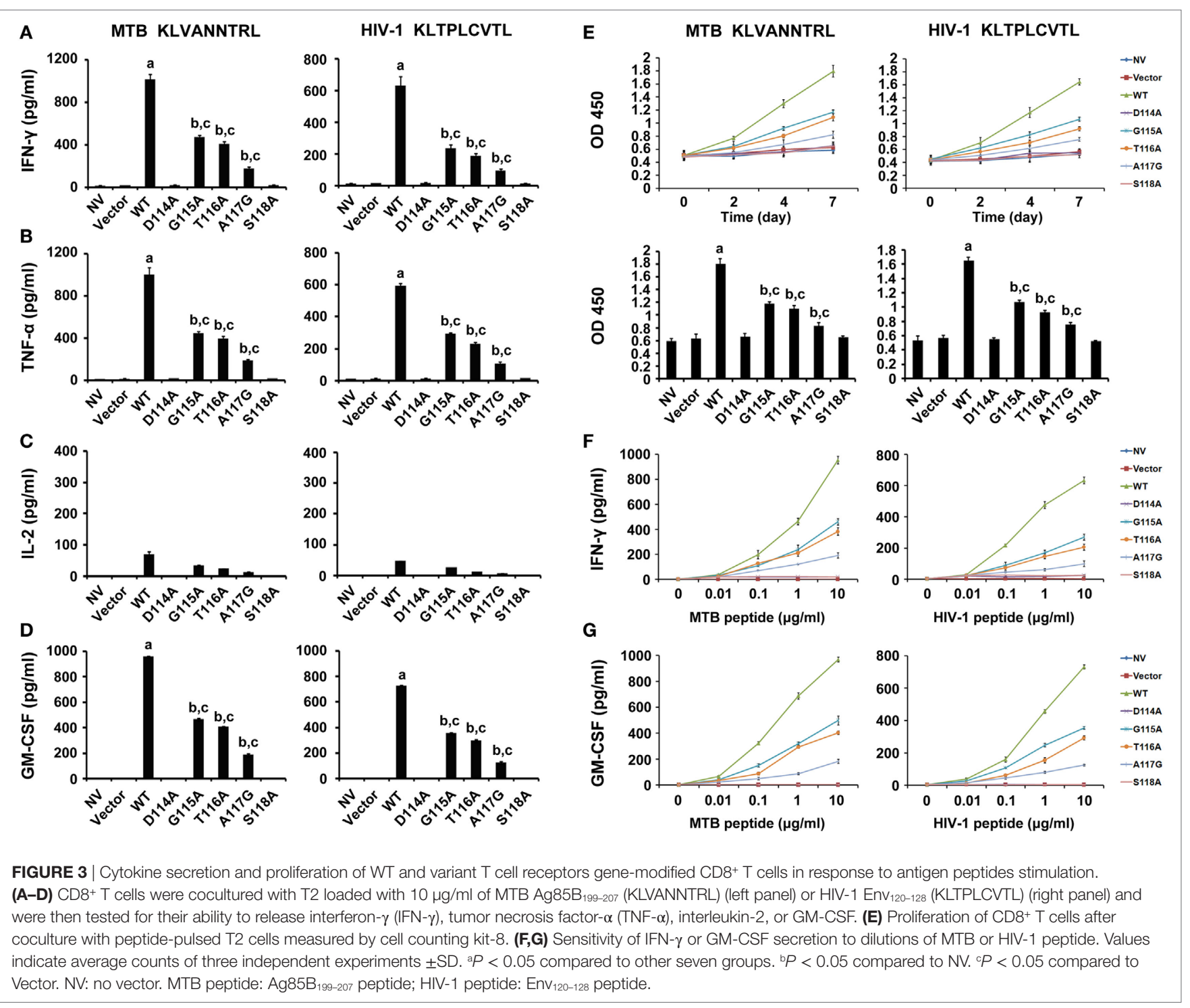


with MTB peptide or HIV-1 peptide-pulsed T2 cells made high amounts of TNF- $\alpha$ compared to untransduced or empty vector transduced T cells $(P<0.05)$, while the D114A and S118A TCR-transduced $\mathrm{CD}^{+} \mathrm{T}$ cells did not $(P>0.05)$ (Figure $3 \mathrm{~B}$ ). $\mathrm{CD}^{+} \mathrm{T}$ cells transduced with the WT, G115A, T116A, or A117G TCR secreted low levels of IL-2, although higher than the other four groups (Figure 3C). Similarly with IFN- $\gamma$ and TNF- $\alpha$, the amount of GM-CSF produced by the WT TCR engineered CD8 ${ }^{+}$ T cells following exposure to T2 cells pulsed with MTB peptide or HIV-1 peptide was significantly higher than that in the other seven groups $(P<0.05)$. CD8 ${ }^{+} \mathrm{T}$ cells expressing the G115A, T116A, or A117G TCR secreted highly elevated levels of GM-CSF in response to MTB peptide or HIV-1 peptide-pulsed T2 cells compared to control groups (untransduced or empty vector transduced group, $P<0.05$ ), while T cells expressing the D114A and S118A TCR failed to produce significant levels of GM-CSF $(P>0.05)$ (Figure 3D).

The relative reactivity of the WT and variant TCRs geneengineered T cells was detected by incubating transduced CD8 ${ }^{+}$ T cells with T2 cells pulsed with limiting dilutions of MTB peptide or HIV-1 peptide (Figures 3F,G). The WT TCR, as well as G115A, T116A, and A117G TCR-transduced T cells, recognized T2 cells pulsed with as little as $0.01 \mu \mathrm{g} / \mathrm{ml}$ MTB peptide or HIV-1 peptide. But cytokines secretion exerted a dramatic reduction in G115A, T116A, and A117G TCR-transduced T cells compared with those in the WT TCR-transduced cultures. In marked contrast, no significant differences in cytokines production were observed in untransduced, empty vector transduced, D114A and S118A TCR-transduced cell populations at every peptide concentration.

Furthermore, intracellular cytokine staining showed that about 53 and $50 \%$ of the WT TCR-engineered $\mathrm{CD}^{+} \mathrm{T}$ cells within the $\mathrm{GFP}^{+}$double dextramers ${ }^{+}$population were positive for intracellular IFN- $\gamma$ in the presence of MTB peptide or HIV-1 peptide, respectively. In contrast, only a very low proportion of IFN- $\gamma$-producing $\mathrm{T}$ cells was observed in the control group following exposure to the irrelevant CMV pp65 ${ }_{495-503}$ peptide-pulsed T2 cells. Compared with the WT TCR-transduced T cells, the G115A, T116A, or A117G TCR transductant when cocultured with T2 cells loaded with MTB peptide or HIV-1 peptide showed a significant decrease in IFN- $\gamma$ secretion (Figure 4).

\section{Antigen-Specific Proliferation of the WT and Variant TCRs-Engineered CD8 ${ }^{+}$ T Cells}

To confirm whether these gene-modified cells would proliferate in vitro, the CCK-8 assay was performed (Figure 3E). The speed of proliferation of WT TCR engineered $\mathrm{CD}^{+} \mathrm{T}$ cells stimulated with MTB peptide or HIV-1 peptide-loaded T2 cells was significantly faster than that in other groups at 2, 4, and 7 days post-stimulation, particularly at day $7(P<0.05)$. CD8 ${ }^{+} \mathrm{T}$ cells transduced with G115A, T116A, and A117G TCR proliferated significantly greater than control groups after exposure to $\mathrm{T} 2$ cells loaded with MTB peptide or HIV-1 peptide, especially on day $7(P<0.05)$. As expected, no obvious differences in proliferation were observed in untransduced, empty vector transduced, D114A and S118A TCR-transduced cells at every time $(P>0.05)$.

\section{Cytolytic Activity of CD8 ${ }^{+} \mathrm{T}$ Cells Expressing the WT and Variant TCRs}

To determine the lytic function of the transduced $\mathrm{CD} 8^{+} \mathrm{T}$ cells, the GrB release and EuTDA cytotoxicity assays were first carried out (Figure 5A). GrB secretion of the WT TCR gene-modified T cells were significantly higher than that in the other seven groups when exposed to T2 cells pulsed with MTB peptide $(P<0.05)$. $\mathrm{CD}^{+} \mathrm{T}$ cells expressing G115A, T116A, and A117G TCR when cocultured with MTB peptide-pulsed T2 cells had higher GrB secretion than control groups $(P<0.05)$, while the D114A and S118A TCR transductants did not $(P>0.05)$. Meanwhile, the WT TCR-transduced T cells readily lysed T2 cells pulsed with MTB peptide. But lysis exerted a significant reduction in G115A, T116A, and A117G TCR gene-modified T cells compared with those in the WT TCR-transduced cells. In contrast, there was little lysis observed in the untransduced, empty vector transduced, D114A and S118A TCR-transduced cells. When T cells exposed to T2 cells pulsed with HIV-1 peptide, the situations of GrB secretion and the percent-specific lysis were the same as those of MTB peptide.

As an additional test of $\mathrm{CD} 8^{+} \mathrm{T}$ cells cytotoxic activity, degranulation measured as cell surface mobilization of CD107a was next determined (Figure 5B). In this experiment, T cells transduced with the WT TCR when cocultured with MTB peptide or HIV-1 peptide-pulsed T2 cells showed a significantly enhanced expression of CD107a compared with the other seven groups. Consistent with the previous experiments, T cells expressing G115A, T116A, and A117G TCR following exposure to T2 cells loaded with MTB peptide or HIV-1 peptide produced significantly higher levels of CD107a than control groups, while the D114A and S118A TCR transductants produced an equivalent level of CD107a compared with untransduced or empty vector transduced group.

\section{Assessment of the Function of WT and Variant TCRs Gene-Modified CD8 ${ }^{+}$T Cells against Endogenous Peptides}

The abilities of $\mathrm{CD}^{+} \mathrm{T}$ cells expressing the $\mathrm{WT}$ and variant TCRs that recognize naturally processed epitopes from MTB and HIV presented by autologous DCs were examined (Figure 6). DCs transfected with the Ag85B-expressing plasmid pV1J.nstPA-Ag85B or the Env-expressing plasmid pCAGGS-Env were cocultured with TCR gene-modified $\mathrm{CD}^{+} \mathrm{T}$ cells. In agreement with expectations, the WT TCR engineered T cells responded to both Ag85B- and Env-expressing plasmids with significantly higher levels of cytokines secretion and lytic function when compared with the other seven groups $(P<0.05)$. Compared with untransduced or empty vector transduced group, $\mathrm{T}$ cells expressing G115A, T116A, and A117G TCR showed significantly elevated activities when exposed to the endogenously presented antigens by DCs $(P<0.05)$, while the D114A and S118A TCR transductants did not $(P>0.05)$.

\section{Expression of CD69 in Genetically Engineered J.RT3-T3.5 Cells}

To further evaluate the properties of the WT and variant TCRs, constructs were transfected into the TCR negative $\mathrm{T}$ cell line 


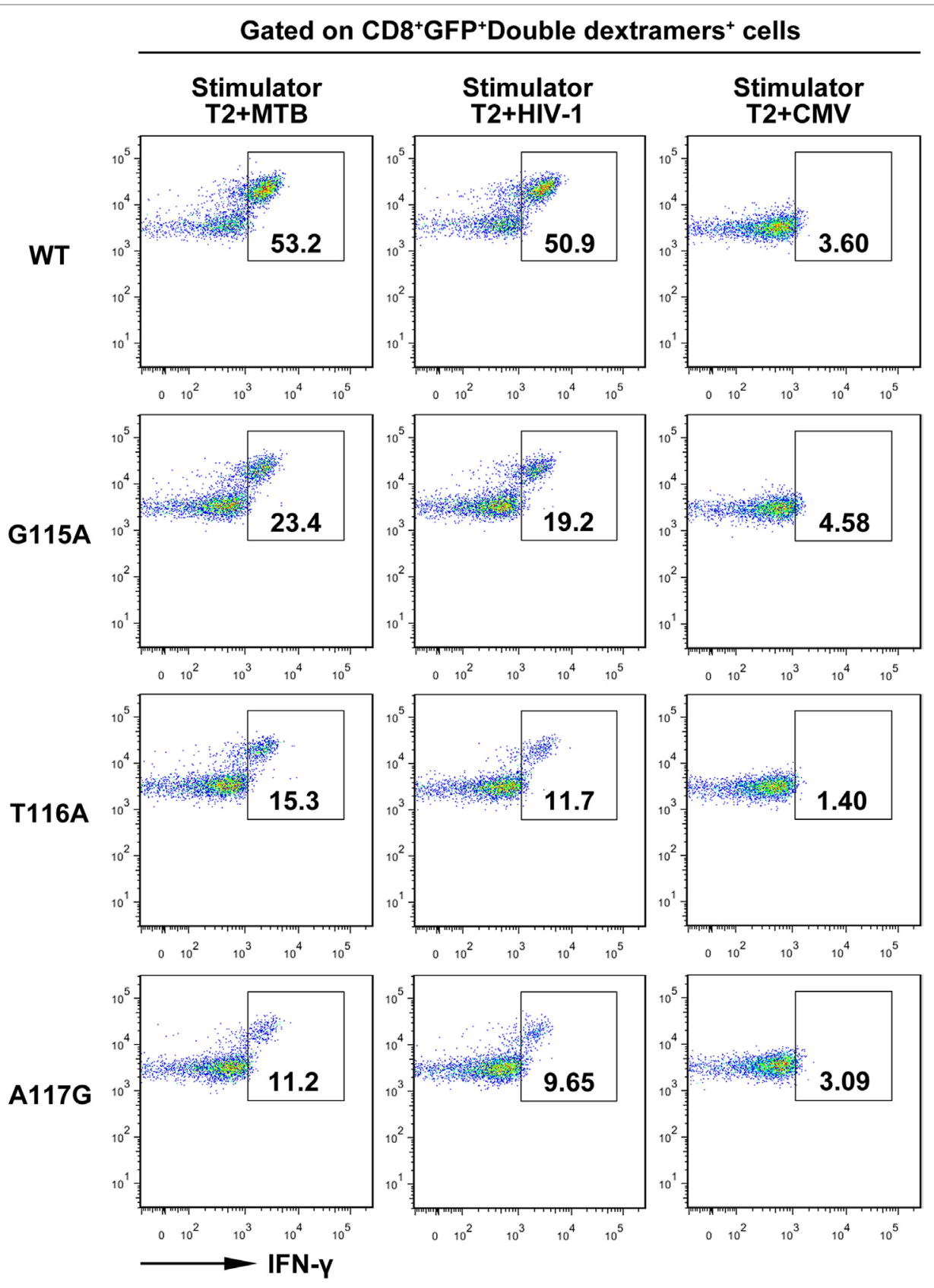

FIGURE 4 | Intracellular staining of transduced CD8 ${ }^{+} \mathrm{T}$ cells for interferon- $\gamma$ (IFN- $\gamma$ ) production. Shown are the resultant FACS scatter plots for CD8+ T cells

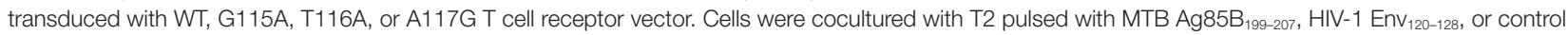
peptide CMV pp65 ${ }_{495-503}$. Cells were gated for $\mathrm{CD}^{+} \mathrm{GFP}^{+}$double dextramers ${ }^{+}$cells and then analyzed for intracellular IFN- $\gamma$.

J.RT3-T3.5. As might be expected, the expression of CD69, which is an immediate marker of early T cell activation in WT TCRtransduced J.RT3-T3.5 cells when incubated with T2 cells pulsed with MTB peptide or HIV-1 peptide showed a significant increase compared with those in the other six groups $(P<0.05)$. CD69 expression of the G115A, T116A, and A117G TCR-transduced J.RT3-T3.5 cells responded to both peptides exhibited a significant increase in contrast to that of empty vector transduced group $(P<0.05)$, while the CD69 expression of D114A and S118A TCR transductants did not $(P>0.05)$. Comparably, no significant increase in CD69 expression was observed in all groups after exposure to T2 cells pulsed with the irrelevant CMV pp65 ${ }_{495-503}$ peptide (Figure 7 ).

\section{DISCUSSION}

In this study, we demonstrated the importance of AAs in the predicted CDR 3 of the bispecific TCR $\beta$-chain in recognition of MTB 


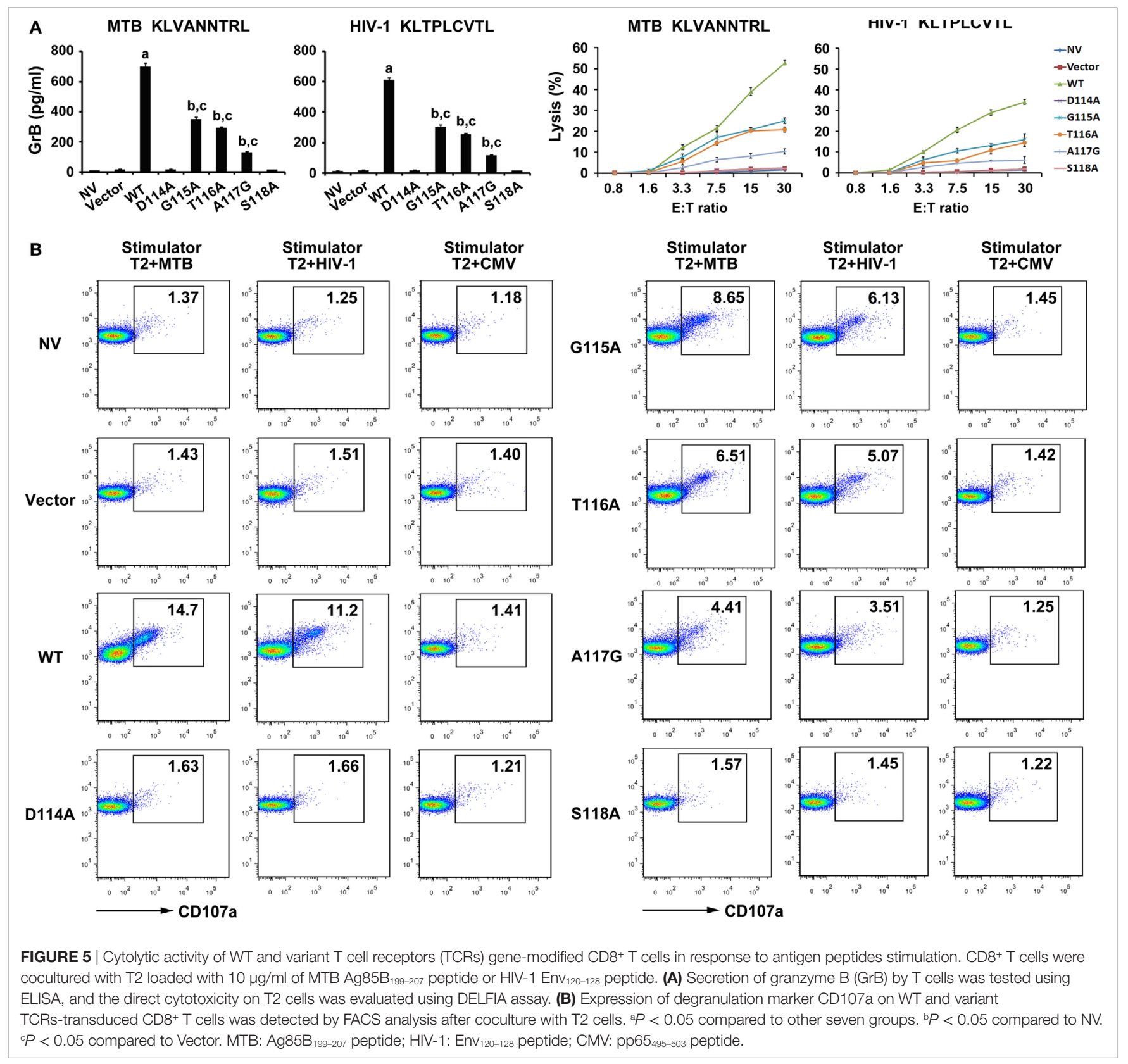

$\mathrm{Ag}_{85 \mathrm{~B}_{199-207}}$ peptide and HIV-1 $\mathrm{Env}_{120-128}$ peptide. It is unlikely that the AA substitutions introduced into the bispecific TCR $\beta 3$ loop disrupt the conformation of the entire TCR. As alanine, the smallest chiral AA, is one of the richest AAs and is both a buried or solvent-exposed residue in protein structures, replacing residues by it, which removes side chains beyond the $\beta$ carbon, should be tolerated in loop structures (30). Actually, dextramer staining with MTB and HIV-1 dextramer demonstrated that the mutant TCRs exhibiting diminished antigen responses retained the peptides recognition by these dextramers (Figure $2 \mathbf{B}$ ). This means that the overall conformations of the mutant TCRs were not disrupted. Of course, there are also some studies proving that alanine substitutions can cause conformational change in the Ig-like molecular CD4 as estimated by antibody binding $(31,32)$. The TCR residues in the $\mathrm{C}, \mathrm{C}^{\prime}, \mathrm{F}$, and $\mathrm{G} \beta$-chains involved in the TCR $\alpha-\beta$ interface presumably have the strongest impact on chain pairing (33). However, we abstained from substituting at these AAs. As a matter of fact, mutant TCRs were effectively expressed in J.RT3-T3.5 cells, which lack surface expression of either $\mathrm{CD} 3$ or the TCR $\alpha / \beta$ heterodimer. The TCR/CD 3 complexes expressed by the transductants were functional, as these cells were capable of expressing CD69 in response to MTB and HIV-1 peptide presented by T2 cells (Figure 7), proving that the AA substitutions in CDR3 $\beta$ disrupted neither association with TCR $\alpha$ chain or CD3 polypeptides, nor signal transduction through the TCR/CD3 complex. Thus, the most likely explanation for the 


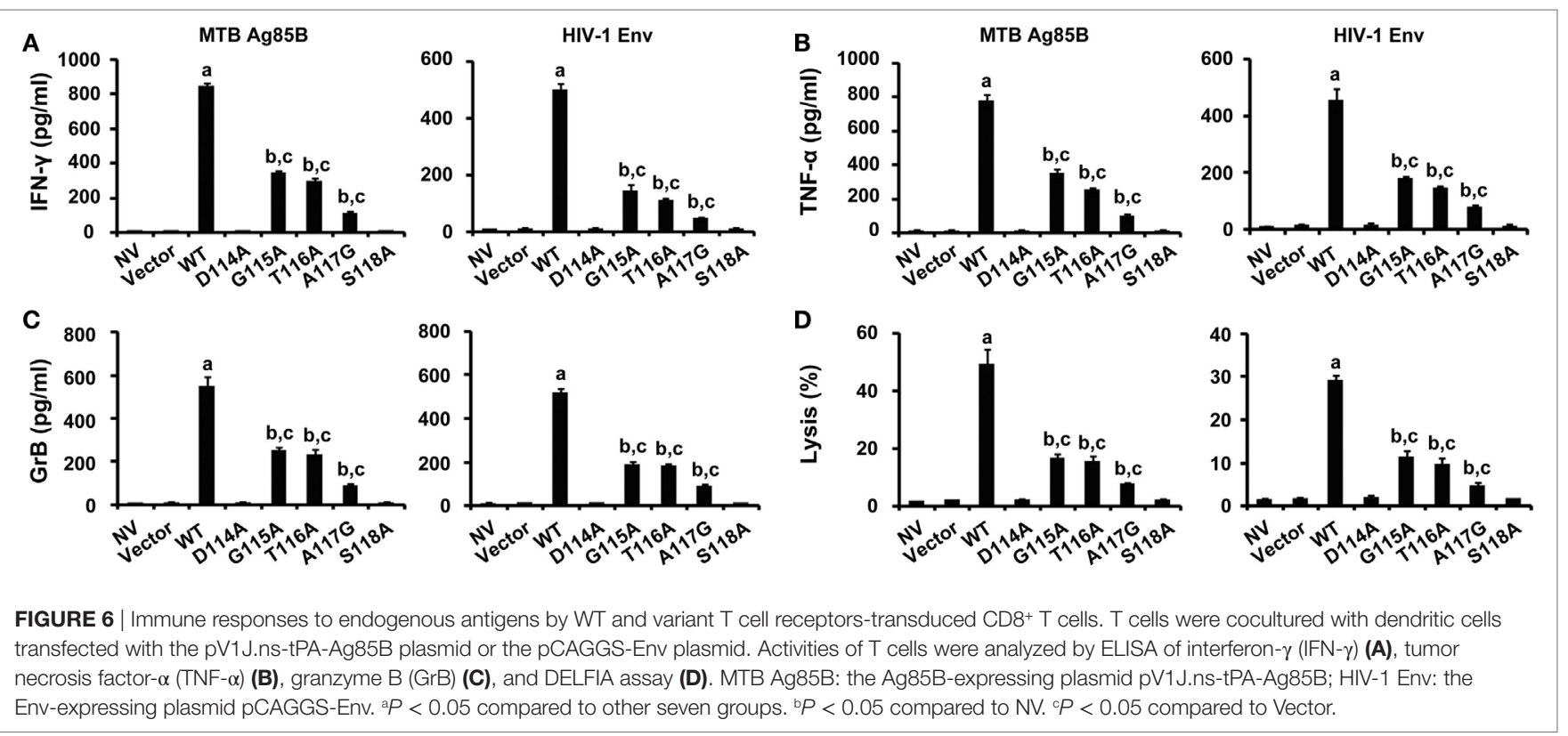

diminished response by the mutant bispecific TCR transductants is that the alanine substitutions change the antigen-binding site on the TCR.

Amino acids in the predicted $\beta 3$ loop of the bispecific TCR seem to be particularly crucial for recognition of peptide-MHC complexes. Mutation of $\mathrm{Asp}^{114}$ or $\mathrm{Ser}^{118}$ to alanine abolished the antigen response. In contrast, the other three residues in the $\beta 3$ loop severely diminished but not abolished ligand recognition when mutated to alanine or glycine (G115A, T116A, A117G). The negatively charged $A s p^{114}$ residue in the CDR3 $\beta$ of the bispecific TCR is required for TCR function. This could be due to the fact that $\mathrm{Asp}^{114}$ is likely to form a salt bridge with a positively charged residue or the positively charged antigen in peptide-MHC complex. A lot of antigen-antibody interfaces include one or more salt bridges (34). The S118A mutation, which removes a single side chain hydroxyl group, eliminated the antigen response, illustrating the significant impact that small structural changes can have on $\mathrm{T}$ cell recognition. The substitution of alanine for $\mathrm{Thr}^{116}$ gives rise to the removal of its methyl and hydroxyl groups, making the side chain relatively smaller. If $\mathrm{Thr}^{116}$ contacts the antigenic peptide, replacement of AAs on the antigenic peptide with bulkier side chains probably compensate for the substitution of alanine for $\mathrm{Thr}^{116}$. This hypothesis had been sufficiently tested in arsonate-conjugated peptide OVA (35).

As mentioned above, we identified the critical residues in the CDR3 $\beta$ of the bispecific TCR in the initial alanine substitution scan. On the basis of the results, single AA substitutions at these five critical residues will be synthesized to produce a 18 AA substitution library (except for the AA at each position and alanine or glycine) at each position by site-directed mutagenesis. Within these AA variants, the high-affinity TCR, which is likely to enhance antigen-specific reactivity in TCR genemodified T cells may be identified. A study of the class II MHC molecular I-A ${ }^{\mathrm{d}}$-restricted D5 TCR, which specifically recognizes arsonate-conjugated peptides, led to the identification of alanine substitutions in TCR CDRs that diminished T cell recognition, as well as substitutions that had no obvious effect, but failed to exhibit substitutions that enhanced $\mathrm{T}$ cell function (36). However, site-directed mutagenesis of the CDR regions of the murine $2 \mathrm{C}$ TCR that recognizes the $\mathrm{H}-2 \mathrm{~K}^{\mathrm{b}}$-restricted peptide as well as the allo-MHC molecule $\mathrm{H}-2 \mathrm{~L}^{\mathrm{d}}$-restricted peptide was performed to identify the high-affinity variants that in the meantime seemed to sustain specificity for the cognate peptide (37). A highaffinity mutant 2C TCR possessing affinity that was 300 -fold higher than the WT TCR significantly increased the response of a CD8-negative $\mathrm{T}$ cell line that expressed the mutant TCR to peptide-loaded target cells (38). Furthermore, AA substitutions in the 1G4 TCR CDR regions, which had higher affinities than the native TCR not only markedly enhanced the ability of $\mathrm{CD}^{+}$ $\mathrm{T}$ cells to recognize the NY-ES0-1/HLA-A*02 complex but also simultaneously showed enhanced antigen-specific reactivity in $\mathrm{CD}^{+} \mathrm{T}$ cells (39).

It has been reported that the exceedingly narrow window of native TCR-peptide-binding affinities, which distinguish between thymic positive and negative selection restricts the activity of the T cells, and T cell activity seems to be connected with the effective clearance of tumor cells and infected cells in vivo (40). Thus, genetically modified $\mathrm{T}$ cells expressing high-affinity TCRs against disease-specific antigens probably have the superior efficacy for adoptive immunotherapy. Carpenter et al. have reported that the primary response mediated by the immunodominant MTB antigen TB10.4-specific $\mathrm{CD} 8^{+} \mathrm{T}$ cells possessing high-affinity TCR outnumbers the memory response mediated by T cells expressing decreased affinity TCR during MTB challenge in mice (41). Ex vivo polyclonal $\mathrm{CD}^{+} \mathrm{T}$ cells efficiently redirected by a high-affinity HIV Gag-specific TCR eliminated $\mathrm{CD}^{+} \mathrm{T}$ cells from HLA-A ${ }^{*} 0201^{+}$antiretroviral therapy-treated patients after reactivation of inducible HIV in vitro (12). Another well-documented example is that PBL-derived T cells genetically engineered with a high-affinity, HLA-A2-restricted, hepatitis 


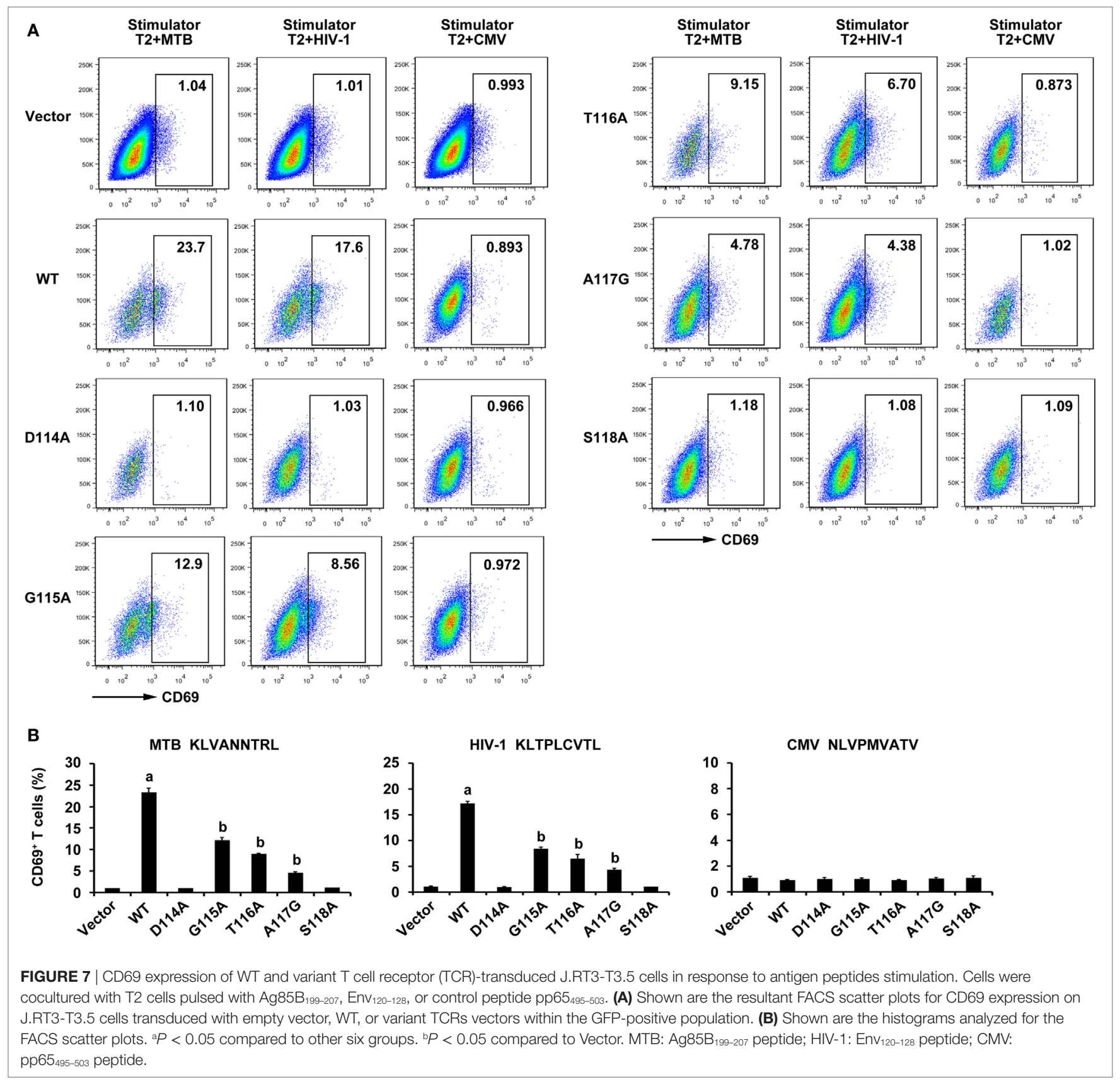

$\mathrm{C}$ virus (HCV) NS3-reactive TCR can recognize naturally processed antigen and elicit CD8-independent recognition of both peptide-loaded targets and $\mathrm{HCV}^{+}$human hepatocellular carcinoma cell lines. Furthermore, these cells can mediate regression of established $\mathrm{HCV}$-associated hepatocellular carcinoma in vivo (11). However, genetically engineered T cells expressing highaffinity TCRs for the treatment of MTB/HIV coinfection have not been reported.

Despite our results have fully proved the importance of the AAs in the predicted CDR3 of the bispecific TCR $\beta$-chain in recognition of the peptide-MHC complexes, we cannot currently exclude the possibility that other regions of the TCR help antigen binding. For example, we should further study the function of the AAs in the $\operatorname{CDR} 1 \beta, \operatorname{CDR} 2 \beta, \operatorname{CDR} 1 \alpha, \operatorname{CDR} 2 \alpha, \operatorname{CDR} 3 \alpha$, as well as the "fourth" hypervariable loop of the bispecific TCR, which has been established the importance of involving in $\mathrm{T}$ cell recognition by a CD1d-restricted TCR (42).

In conclusion, our experiments indicated that three of the five substituted residues in CDR3 $\beta$ of the bispecific TCR significantly decreased $\mathrm{T}$ cell response, whereas the other two substituted residues completely abolished the antigen response. These results will provide an imperative foundation for generating the improved high-affinity bispecific TCR for use in T cell adoptive immunotherapy for MTB/HIV coinfected patients. 


\section{ETHICS STATEMENT}

This study was carried out in accordance with the recommendations of the International Committee of Medical Journal Editors and the ethics committee of the Southern Medical University with written informed consent from all subjects. All subjects gave written informed consent in accordance with the Declaration of Helsinki. The protocol was approved by the ethics committee of the Southern Medical University.

\section{AUTHOR CONTRIBUTIONS}

C-YZ participated in the cell experiments, substantially contributed to molecular biology studies and immunoassays, performed the statistical analysis, and drafted the manuscript. R-NW participated in interpretation of data and molecular biology studies. QW participated in research design, cell and virus infection experiments, and molecular biology studies. W-TH and S-MZ

\section{REFERENCES}

1. Bruchfeld J, Correia-Neves M, Kallenius G. Tuberculosis and HIV coinfection. Cold Spring Harb Perspect Med (2015) 5:a017871. doi:10.1101/cshperspect. a017871

2. WHO. Global Tuberculosis Report 2016. Geneva, Switzerland: WHO (2016).

3. Abdool Karim SS, Naidoo K, Grobler A, Padayatchi N, Baxter C, Gray A, et al. Timing of initiation of antiretroviral drugs during tuberculosis therapy. N Engl J Med (2010) 362:697-706. doi:10.1056/NEJMoa0905848

4. Lai RP, Meintjes G, Wilkinson RJ. HIV-1 tuberculosis-associated immune reconstitution inflammatory syndrome. Semin Immunopathol (2016) 38:185-98. doi:10.1007/s00281-015-0532-2

5. Berger C, Turtle CJ, Jensen MC, Riddell SR. Adoptive transfer of virus-specific and tumor-specific T cell immunity. Curr Opin Immunol (2009) 21:224-32. doi:10.1016/j.coi.2009.02.010

6. Smith LL, Wright BL, Buckley RH. Successful treatment of disseminated BCG in a patient with severe combined immunodeficiency. J Allergy Clin Immunol Pract (2015) 3:438-40. doi:10.1016/j.jaip.2014.12.004

7. Tebas P, Stein D, Tang WW, Frank I, Wang SQ, Lee G, et al. Gene editing of CCR5 in autologous CD4 T cells of persons infected with HIV. N Engl J Med (2014) 370:901-10. doi:10.1056/NEJMoa1300662

8. Dudley ME, Wunderlich JR, Shelton TE, Even J, Rosenberg SA. Generation of tumor-infiltrating lymphocyte cultures for use in adoptive transfer therapy for melanoma patients. J Immunother (2003) 26:332-42. doi:10.1097/00002371200307000-00005

9. Morgan RA, Dudley ME, Wunderlich JR, Hughes MS, Yang JC, Sherry RM, et al. Cancer regression in patients after transfer of genetically engineered lymphocytes. Science (2006) 314:126-9. doi:10.1126/science.1129003

10. Zha X, Xu L, Chen S, Yang L, Zhang Y, Lu Y, et al. Generation of V alpha13/ beta21+ T cell specific target CML cells by TCR gene transfer. Oncotarget (2016) 7:84246-57. doi:10.18632/oncotarget.12441

11. Spear TT, Callender GG, Roszkowski JJ, Moxley KM, Simms PE, Foley KC, et al. TCR gene-modified T cells can efficiently treat established hepatitis $\mathrm{C}$-associated hepatocellular carcinoma tumors. Cancer Immunol Immunother (2016) 65:293-304. doi:10.1007/s00262-016-1800-2

12. Yang H, Buisson S, Bossi G, Wallace Z, Hancock G, So C, et al. Elimination of latently HIV-infected cells from antiretroviral therapy-suppressed subjects by engineered immune-mobilizing T-cell receptors. Mol Ther (2016) 24:1913-25. doi:10.1038/mt.2016.114

13. Schub A, Schuster IG, Hammerschmidt W, Moosmann A. CMV-specific TCR-transgenic T cells for immunotherapy. J Immunol (2009) 183:6819-30. doi:10.4049/jimmunol.0902233

14. Gottschalk S, Heslop HE, Rooney CM. Adoptive immunotherapy for EBVassociated malignancies. Leuk Lymphoma (2005) 46:1-10. doi:10.1080/ 10428190400002202 participated in cell and virus infection experiments. X-LD and $\mathrm{J}$-HY participated in cell culture, immunoassay, and interpretation of data. LM conceived of the study and participated in its design and coordination and revised the manuscript critically. All authors read and approved the final manuscript.

\section{FUNDING}

This work was supported by the National Natural Science Foundation of China (81571951, 81371764), National Science and Technology Key Projects on Major Infectious Diseases (2017ZX10201301-008), Guangdong Natural Science Foundation (2016A030311001), Science and Technology Project of Guangdong Province (2017A020212007), Science and Technology Project of Guangzhou (201707010215), the Guangdong Province Universities and Colleges Pearl River Scholar Funded Scheme (2012), and the China Postdoctoral Science Foundation (2016M600661).

15. Manning TC, Kranz DM. Binding energetics of T-cell receptors: correlation with immunological consequences. Immunol Today (1999) 20:417-22. doi:10.1016/S0167-5699(99)01508-X

16. van der Merwe PA, Davis SJ. Molecular interactions mediating T cell antigen recognition. Annu Rev Immunol (2003) 21:659-84. doi:10.1146/annurev. immunol.21.120601.141036

17. Cole DK, Pumphrey NJ, Boulter JM, Sami M, Bell JI, Gostick E, et al. Human TCR-binding affinity is governed by MHC class restriction. J Immunol (2007) 178:5727-34. doi:10.4049/jimmunol.178.9.5727

18. Varela-Rohena A, Molloy PE, Dunn SM, Li Y, Suhoski MM, Carroll RG, et al. Control of HIV-1 immune escape by CD8 T cells expressing enhanced T-cell receptor. Nat Med (2008) 14:1390-5. doi:10.1038/ nm. 1779

19. Savage PA, Davis MM. A kinetic window constricts the $\mathrm{T}$ cell receptor repertoire in the thymus. Immunity (2001) 14:243-52. doi:10.1016/S10747613(01)00106-6

20. Laugel B, van den Berg HA, Gostick E, Cole DK, Wooldridge L, Boulter J, et al. Different $\mathrm{T}$ cell receptor affinity thresholds and CD8 coreceptor dependence govern cytotoxic $\mathrm{T}$ lymphocyte activation and tetramer binding properties. J Biol Chem (2007) 282:23799-810. doi:10.1074/jbc.M700976200

21. Feng D, Bond CJ, Ely LK, Maynard J, Garcia KC. Structural evidence for a germline-encoded $\mathrm{T}$ cell receptor-major histocompatibility complex interaction 'codon'. Nat Immunol (2007) 8:975-83. doi:10.1038/ni1502

22. Wu LC, Tuot DS, Lyons DS, Garcia KC, Davis MM. Two-step binding mechanism for T-cell receptor recognition of peptide MHC. Nature (2002) 418:552-6. doi:10.1038/nature00920

23. Manning TC, Schlueter CJ, Brodnicki TC, Parke EA, Speir JA, Garcia KC et al. Alanine scanning mutagenesis of an alphabeta $\mathrm{T}$ cell receptor: mapping the energy of antigen recognition. Immunity (1998) 8:413-25. doi:10.1016/ S1074-7613(00)80547-6

24. Parkhurst MR, Joo J, Riley JP, Yu Z, Li Y, Robbins PF, et al. Characterization of genetically modified T-cell receptors that recognize the CEA:691-699 peptide in the context of HLA-A2.1 on human colorectal cancer cells. Clin Cancer Res (2009) 15:169-80. doi:10.1158/1078-0432.CCR-08-1638

25. Hughes MS, Yu YY, Dudley ME, Zheng Z, Robbins PF, Li Y, et al. Transfer of a TCR gene derived from a patient with a marked antitumor response conveys highly active T-cell effector functions. Hum Gene Ther (2005) 16:457-72. doi:10.1089/hum.2005.16.457

26. Frigstad T, Loset GA, Sandlie I, Bogen B. A public T cell receptor recognized by a monoclonal antibody specific for the D-J junction of the beta-chain. Scand J Immunol (2013) 78:345-51. doi:10.1111/sji.12098

27. Zhou CY, Wen Q, Chen XJ, Wang RN, He WT, Zhang SM, et al. Human CD8(+) T cells transduced with an additional receptor bispecific for both Mycobacterium tuberculosis and HIV-1 recognize both epitopes. J Cell Mol Med (2016) 20:1984-98. doi:10.1111/jcmm.12878 
28. Wilgenhof S, Corthals J, Heirman C, van Baren N, Lucas S, Kvistborg P, et al. Phase II study of autologous monocyte-derived mRNA electroporated dendritic cells (TriMixDC-MEL) plus ipilimumab in patients with pretreated advanced melanoma. J Clin Oncol (2016) 34:1330-8. doi:10.1200/ JCO.2015.63.4121

29. Chinnasamy N, Wargo JA, Yu Z, Rao M, Frankel TL, Riley JP, et al. A TCR targeting the HLA-A*0201-restricted epitope of MAGE-A3 recognizes multiple epitopes of the MAGE-A antigen superfamily in several types of cancer. J Immunol (2011) 186:685-96. doi:10.4049/jimmunol.1001775

30. Matthews BW. Structural and genetic analysis of protein stability. Annu Rev Biochem (1993) 62:139-60. doi:10.1146/annurev.bi.62.070193.001035

31. Wang JH, Yan YW, Garrett TP, Liu JH, Rodgers DW, Garlick RL, et al. Atomic structure of a fragment of human CD4 containing two immunoglobulin-like domains. Nature (1990) 348:411-8. doi:10.1038/348411a0

32. Ryu SE, Kwong PD, Truneh A, Porter TG, Arthos J, Rosenberg M, et al. Crystal structure of an HIV-binding recombinant fragment of human CD4. Nature (1990) 348:419-26. doi:10.1038/348419a0

33. Chothia C, Boswell DR, Lesk AM. The outline structure of the T-cell alpha beta receptor. EMBO J (1988) 7:3745-55.

34. Burkovitz A, Ofran Y. Understanding differences between synthetic and natural antibodies can help improve antibody engineering. MAbs (2016) 8:278-87. doi:10.1080/19420862.2015.1123365

35. Lascombe MB, Alzari PM, Boulot G, Saludjian P, Tougard P, Berek C, et al. Three-dimensional structure of Fab R19.9, a monoclonal murine antibody specific for the p-azobenzenearsonate group. Proc Natl Acad Sci U S A (1989) 86:607-11. doi:10.1073/pnas.86.2.607

36. Kasibhatla S, Nalefski EA, Rao A. Simultaneous involvement of all six predicted antigen binding loops of the T cell receptor in recognition of the MHC/ antigenic peptide complex. J Immunol (1993) 151:3140-51.

37. Chlewicki LK, Holler PD, Monti BC, Clutter MR, Kranz DM. High-affinity, peptide-specific $\mathrm{T}$ cell receptors can be generated by mutations in CDR1, CDR2 or CDR3. J Mol Biol (2005) 346:223-39. doi:10.1016/j.jmb.2004.11.057
38. Holler PD, Lim AR, Cho BK, Rund LA, Kranz DM. CD8(-) T cell transfectants that express a high affinity $\mathrm{T}$ cell receptor exhibit enhanced peptide-dependent activation. J Exp Med (2001) 194:1043-52. doi:10.1084/jem.194.8.1043

39. Robbins PF, Li YF, El-Gamil M, Zhao Y, Wargo JA, Zheng Z, et al. Single and dual amino acid substitutions in TCR CDRs can enhance antigen-specific T cell functions. J Immunol (2008) 180:6116-31. doi:10.4049/jimmunol.180.9.6116

40. Zeh HJ III, Perry-Lalley D, Dudley ME, Rosenberg SA, Yang JC. High avidity CTLs for two self-antigens demonstrate superior in vitro and in vivo antitumor efficacy. J Immunol (1999) 162:989-94.

41. Carpenter SM, Nunes-Alves C, Booty MG, Way SS, Behar SM. A higher activation threshold of memory $\mathrm{CD}^{+} \mathrm{T}$ cells has a fitness cost that is modified by TCR affinity during tuberculosis. PLoS Pathog (2016) 12:e1005380. doi:10.1371/journal.ppat.1005380

42. Paletta D, Fichtner AS, Hahn AM, Starick L, Beyersdorf N, MonzonCasanova E, et al. The hypervariable region 4 (HV4) and position 93 of the alpha chain modulate CD1d-glycolipid binding of iNKT TCRs. Eur J Immunol (2015) 45:2122-33. doi:10.1002/eji.201545534

Conflict of Interest Statement: The authors declare that the research was conducted in the absence of any commercial or financial relationships that could be construed as a potential conflict of interest.

The reviewer, IO, and handling editor declared their shared affiliation and the handling editor states that the process nevertheless met the standards of a fair and objective review.

Copyright ( $(2017$ Zhou, Wang, Wen, He, Zhang, Du, Yang and Ma. This is an openaccess article distributed under the terms of the Creative Commons Attribution License (CC BY). The use, distribution or reproduction in other forums is permitted, provided the original author(s) or licensor are credited and that the original publication in this journal is cited, in accordance with accepted academic practice. No use, distribution or reproduction is permitted which does not comply with these terms. 